\title{
TERAPIAS BASADAS EN LA TECNOLOGÍA DE ARN DE INTERFERENCIA: UNA NUEVA CLASE DE FÁRMACOS PARA EL TRATAMIENTO DE PATOLOGÍAS OCULARES
}

\section{RNA INTERFERENCES THERAPEUTICS: A NEW APPROACH TO THE TREATMENT OF OCULAR DISEASES}

\author{
JIMÉNEZ AI ${ }^{1}$
}

Las primeras observaciones del fenómeno de ARN de interferencia (ARNi) se realizaron en 1990 en organismos vegetales. Con la finalidad de obtener petunias de un color más intenso, se adicionaron copias extra a las plantas del gen que codifica ese color. Para sorpresa de los propios investigadores, las petunias transgénicas resultantes eran bicolor y algunas completamente blancas. Lo que indicaba que no sólo habían sido reprimidos los transgenes sino también aquellos nativos de la planta. A este fenómeno se le conoció como silenciamiento genético post transcripcional (SGPT o PTGS). Posteriormente en 1998, Fire y colaboradores describieron por vez primera el fenómeno de interferencia génica o ARNi. Observaron que la inyección de ADN de doble cadena (dsDNA) dentro del nematodo Caenorhabditis elegans producía el silenciamiento específico del gen de secuencia complementaria a la introducida (1). El mecanismo de actuación a nivel molecular fue descrito poco después en extractos de embriones de Drosophila melanogaster (2). En éstos se observó que fragmentos largos de dsDNA podían ser fragmentados en pequeños trozos de 22 nucleótidos y que la introducción de fragmentos de 21 ó 22 nucleótidos sintetizados químicamente facilitaban la degradación del ARN homólogo. Actualmente, el fenómeno de interferencia de la expresión génica mediado por pequeños ARN interferentes endógenos o siRNA se ha reconocido como una estrategia biológica que ocurre en la mayoría de los organismos eucariotas.

Actualmente existen un gran número de evidencias bioquímicas y genéticas que han proporcionado la elucidación del mecanismo de acción de los
ARNi y sobre cómo producen la degradación del ARN mensajero (ARNm) diana (fig. 1). La introducción de ARN de doble hebra (dsRNA) en una célula u organismo inicia una compleja cascada que termina con la degradación del ARNm. El proceso, localizado en el citoplasma, comienza cuando la proteína Dicer captura ARN de doble cadena largos y los fragmenta produciendo siRNA (short interferente RNA) de 21-25 nt. Los siRNA, endógenos o introducidos artificialmente en las células, son incorporados dentro de un complejo multiproteico denominado RISC (RNA- inducing silencing complex). Durante esta unión, los siRNA de doble cadena son desapareados y la hebra antisentido que queda unida guiará a este complejo en la búsqueda de la secuencia homóloga del ARNm diana. Una vez encontrada la secuencia complementaria, se aparea con el siRNA y se produce la rotura endonucleotídica, mediante la proteína Dicer, que degrada el

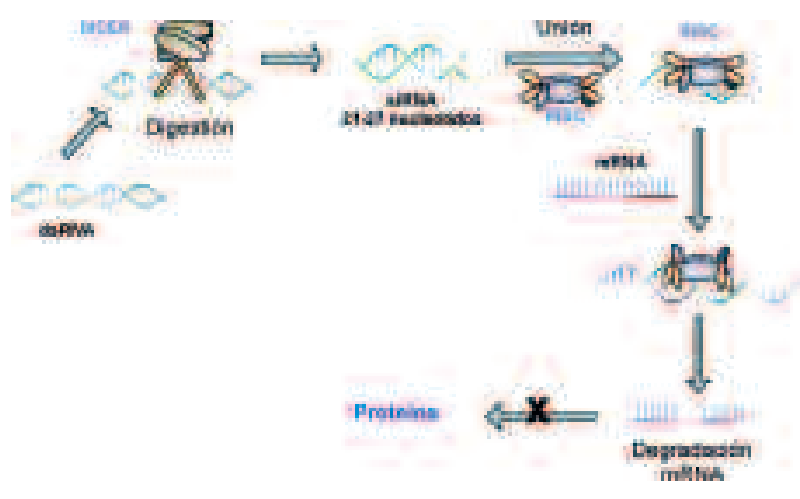

Fig. 1: Mecanismo de acción del RNA de interferencia.

\footnotetext{
1 Directora I+D de Sylentis. Madrid.

E-mail: aijimenez@sylentis.com
} 
Tabla I. Desarrollo farmacéutico de diferentes patologías oculares empleando la tecnología del ARNi

\begin{tabular}{|c|c|c|c|c|c|}
\hline Fármaco & Indicación & Mecanismo de acción & $\begin{array}{l}\text { Fase de desarrollo } \\
\text { farmaceútico }\end{array}$ & País & Empresa \\
\hline Bevasiranib & $\begin{array}{l}\text { Degeneración macular } \\
\text { asociada a la edad } \\
\text { Edema diabético macular }\end{array}$ & RNA de interferencia & Fase II & USA & Acuity Pharmaceutical \\
\hline SIRNA-027 & Degeneración macular & ARN de interferencia & Fase I & USA & Sirna Therapeutics-MERK \\
\hline RTP801i & $\begin{array}{l}\text { Degeneración macular } \\
\text { asociada a la edad }\end{array}$ & ARN de interferencia & Fase I & Alemania & Atugen-Quark Biothec \\
\hline $\mathrm{I}+\mathrm{D}$ & Retinitis citomegalovirus & ARN de interferencia & Preclínica & USA & RXI Pharmaceutical \\
\hline $\mathrm{I}+\mathrm{D}$ & Patologías oculares & ARN de interferencia & Preclínica & USA & ZaBeCOR Pharmaceutical \\
\hline $\mathrm{I}+\mathrm{D}$ & $\begin{array}{l}\text { Degeneración macular } \\
\text { asociada a la edad }\end{array}$ & ARN de interferencia & Preclínica & USA & Alnylam Pharmaceuticals \\
\hline $\mathrm{I}+\mathrm{D}$ & Glaucoma & ARN de interferencia & Preclínica & España & Sylentis \\
\hline
\end{tabular}

tránscrito del gen de interés. Es importante apuntar al hecho de que uno de los factores clave que intervienen en el mantenimiento y efectividad de la interferencia, es la capacidad que tiene el mecanismo de silenciamiento de no llevar asociado ningún tipo de respuesta inmune (3).

El fenómeno del ARNi constituye una auténtica revolución en Biología, de hecho en el año 2003 la revista Science determinó que la tecnología del ARNi fue el descubrimiento más revelante de este año. Además recientemente se ha concedido el Premio Nobel de Fisiología y Medicina a los doctores Andrew Fire, del Instituto Tecnológico de Massachussets, y Craig Mello, de la Universidad de Harvard, por su trabajo en ARNi, lo que demuestra la trascendencia de este descubrimiento.

El ARNi es una potente herramienta que está sufriendo un gran desarrollo con fines terapéuticos, debido principalmente a dos hechos: todas la células contienen la maquinaria para llevar a cabo el ARN de interferencia y todos los genes son dianas potenciales. Esta tecnología presenta ventajas frente a la investigación de terapias convencionales, ya que se incluye un desarrollo racional a partir del conocimiento de la diana terapéutica sobre la que se quiere actuar, una gran especificidad de acción y un reducido número de efectos secundarios.

Los siRNA están empezando a ser introducidos en programas clínicos para el establecimiento y desarrollo de terapias basadas en esta tecnología (4) y, para ello, se están siguiendo estrategias similares a las llevadas a cabo con los nucleótidos antisentido. Los ensayos preliminares están demostrando el gran potencial terapéutico de estas moléculas.
En este sentido, el tratamiento de enfermedades oculares está sufriendo un gran desarrollo debido a que el ojo es un órgano relativamente aislado, lo que posibilita el desarrollo de aplicaciones locales. Este tipo de aplicaciones presentan numerosas ventajas, ya que permiten reducir los efectos secundarios y la cantidad de producto (5). Una de las primeras patologías oculares donde se están desarrollando terapias basadas en ARNi es en la neovascularización ocular. Reich y colaboradores (6) han analizado el posible tratamiento de afecciones de la retina, confirmado la factibilidad de la terapia. Han demostrado, en un modelo de degeneración macular en ratón, que la inyección ocular de siRNA silencia la sobreexpresión del receptor de VEGF, causa principal de la enfermedad. Kim y colaboradores (7), han llevado a cabo un estudio similar en el que, silenciando tanto el VEGF como su receptor con aplicaciones locales y sistémicas de siRNA específicos, han impedido el desarrollo de queratitis estromales y de neovascularización inducida por la infección con el virus Herpes. Más recientemente, y siguiendo con las líneas de investigación anteriormente comentadas, Acuity Pharmaceuticals ha despuntado como la primera compañía en incluir siRNAs terapéuticos en ensayos clínicos con humanos. La molécula lanzada se llama Bevasiranib y es un siRNA, capaz de silenciar la expresión de VEGF, efectivo en el tratamiento de la degeneración macular y de la retinopatía diabética. Los estudios preclínicos han demostrado, en un modelo de primate, que una sola aplicación de dicho compuesto reduce significativamente la neovascularización de una manera dosis dependiente y que es capaz de 
mantener sus efectos durante cinco días. En cuanto a los ensayos de Fase I en humanos, este producto ha mostrado que su administración es segura y bien tolerada en 15 individuos sanos. Mientras que en los ensayos de Fase II ha observado que el producto es eficaz y tolerado tras la administración en 129 pacientes con degeneración macular. Por otro lado, Sirna Therapeutics, con el compuesto siRNA-027, siRNA frente al receptor de VGF VGFR1, también ha demostrado una clara eficacia del compuesto tras la administración mediante inyección intravítrea y no ha presentado ningún efecto adverso en la Fase I. Por último, se han comenzado recientemente ensayos clínicos de Fase I con una tercera molécula desarrollada por la alemana Atugen AG, denominada RTP801i, de nuevo en degeneración macular asociada a la edad. Además de en degeneración macular, debe destacarse el desarrollo de esta nueva tecnología para otras patologías oculares como el glaucoma, la renitinis y la retinopatía diabética.

En resumen, el descubrimiento del ARNi ha expandido enormemente el conocimiento científico sobre los mecanismos implicados en la regulación génica. Además el desarrollo de tecnologías basadas en ARNi ha proporcionado a la comunidad científica una poderosa herramienta experimental para el estudio de la funcionalidad génica. La adap- tación de esta tecnología a la biomedicina, aunque aún en desarrollo, ha abierto expectativas terapéuticas sin precedentes.

\section{BIBLIOGRAFÍA}

1. Fire A, Xu S, Montgomery $M K$, Kostas SA, Driver SE, Mello CC. Potent and specific genetic interference by double-stranded RNA in Caenorhabditis elegans. Nature 1998; 391: 806-811.

2. Kennerdell JR, Carthew RW. Use of dsRNA-mediated genetic interference to demonstrate that frizzled and frizzled 2 act in the wingless pathway. Cell 1998; 95: 10171026.

3. Hannon GJ. RNA interference. Nature 2002; 418: 244251.

4. Bumcrot D, Manoharan M, Koteliansky V, Sah DW. RNAi therapeutics: a potential new class of pharmaceutical drugs. Nat Chem Biol 2006; 2: 711-719.

5. Campochiaro PA. Potential applications for RNAi to probe pathogenesis and develop new treatments for ocular disorders. Gene Ther 2006; 13: 559-562.

6. Reich SJ, Fosnot J, Kuroki A, Tang W, Yang X, Maguire $A M$, et al. Small interfering RNA (siRNA) targeting VEGF effectively inhibits ocular neovascularization in a mouse model. Mol Vis 2003; 9: 210-216.

7. Kim B, Tang Q, Biswas PS, Xu J, Schiffelers RM, Xie FY, et al. Inhibition of ocular angiogenesis by siRNA targeting vascular endothelial growth factor pathway genes: therapeutic strategy for herpetic stromal keratitis. Am J Pathol 2004; 165: 2177-2185. 